CLINICAL STUDY

\title{
Women gain weight and fat mass despite lipectomy at abdominoplasty and breast reduction
}

\author{
A S Rinomhota, D U S Bulugahapitiya ${ }^{1}$, S J French ${ }^{2}, \mathrm{C}$ M Caddy ${ }^{3}$, R W Griffiths ${ }^{3}$ and R J M Ross ${ }^{2}$ \\ School of Healthcare, University of Leeds, Leeds, LS2 9JT UK, ${ }^{1}$ Academic Unit of Diabetes, Endocrinology and Metabolism, Royal Hallamshire Hospital, \\ University of Sheffield, Glossop Road, Sheffield, S1O 2JF, UK, ${ }^{2}$ MARS Confectionery, Sheffield, UK and ${ }^{3}$ Department of Plastic and Reconstructive Surgery, \\ Northern General Hospital, Sheffield, S57 $7 A U$ UK \\ (Correspondence should be addressed to R J M Ross; Email: r.j.ross@sheffield.ac.uk)
}

\begin{abstract}
Objectives: In animal models, fat removal results in compensatory weight gain. No study has reported measurement of weight following lipectomy in humans. We have examined changes in weight in patients who underwent lipectomy.

Methods: In a retrospective analysis, 16 patients who had abdominoplasty and 17 patients who underwent bilateral breast reduction were compared with 16 patients who had carpal tunnel syndrome release. Following this, a prospective study was carried out on 7 subjects awaiting abdominoplasty and 12 subjects awaiting bilateral breast reduction surgery.

Results: In the retrospective study, all three patient groups gained weight following surgery. The abdominoplasty group was heavier before surgery and showed greatest weight gain but there was no statistically significant difference in weight gain between the groups. In the prospective study, the abdominoplasty group had a mean fat removal of $1.77 \mathrm{~kg}$ and breast reduction group had a mean of $3.22 \mathrm{~kg}$. Eighteen months following surgery the abdominoplasty group showed a significant mean increase in body weight (mean increase: $4.82 \mathrm{~kg}$ ) and body mass index (BMI) (mean increase: $1.66 \mathrm{~kg} / \mathrm{m}^{2}$ ). In the bilateral breast reduction group, there was a non-significant mean gain in weight (mean increase: $0.67 \mathrm{~kg}$ ) and BMI (mean increase: $0.21 \mathrm{~kg} / \mathrm{m}^{2}$ ).

Conclusions: Patients undergoing lipectomy during abdominoplasty and bilateral breast reduction will gain weight in the long term. This weight gain probably reflects the expected gain in weight without surgery as a similar finding is observed in patients who have undergone surgery without lipectomy. These results highlight the limitation of lipectomy as a weight control measure.
\end{abstract}

European Journal of Endocrinology 158 349-352

\section{Introduction}

Change in weight has not been reported in women who have undergone surgical removal of fat. In a review of 631 patients who underwent liposuction, it was reported that $\sim 80 \%$ were able to maintain a stable post-operative weight but no details of weight were given (1). Cardiovascular risk profile does not appear to improve after liposuction $(2,3)$, although insulin sensitivity has been reported to improve (4) but not in all studies (2). In animal models, the removal of fat results in compensatory weight gain (5-9). It has been suggested that this is mediated by a blood-borne factor as serum from lipectomised rats stimulated proliferation of pre-adipocytes in vitro (10), but intriguingly fat transplantation does not appear to result in compensatory fat loss (11). A questionnaire survey of patients who had undergone blunt suction lipectomy suggested that in humans there is compensatory development of fatty tissue at nontreated locations although these patients were not reviewed and no direct measurements were taken by the researchers (12). Lipectomy surgery has been performed in humans over many years and it is surprising that no study has reported on the relationship between lipectomy and body weight gain. We now report retrospective and prospective studies of weight change following lipectomy surgery.

\section{Methods}

The study was approved by the North Sheffield Local Ethics Committee and patients gave informed written consent.

\section{Retrospective study}

A retrospective study was performed in women aged 18-65 years who had undergone surgery in the last 2 years for abdominoplasty $(n=16)$, bilateral breast reduction $(n=17)$ and carpal tunnel syndrome release $(n=16)$. The carpal tunnel syndrome release group was the control group as they had no fat removed. 
Patients' details are shown in Table 1. Initial data were collected from patients' medical records.

Consented patients were invited for follow-up and body weight, height measurements and body composition were recorded. The body weight was measured using a stand on digital electronic scale, height was measured using traditional stadiometer and body composition was measured by bioelectrical impedance technique using body stat 1500 .

\section{Prospective study}

A prospective study was carried out on 19 healthy females aged 18-59 years who were awaiting elective reconstructive aesthetic surgery (Table 2). These subjects were either normal weight, overweight or obese. Out of these, 7 subjects had abdominoplasty while 12 subjects had bilateral breast reduction. Patients on drugs that can affect energy expenditure and patients with metabolic conditions such as diabetes, thyrotoxicosis and myxoedema were excluded. Patients were reviewed before surgery, 4 weeks after surgery and at the end of 18 months. On all three occasions weight, height and body composition were measured.

Data were analysed by SPSS version 10.0 Chicago, Illinois, USA for Windows using ANOVA between groups with post hoc Bonferroni adjusted comparisons. Significance was accepted at the level of $0.05 \%$.

\section{Results}

\section{Retrospective study}

All three groups in the retrospective study showed significant weight and body mass index (BMI) gain following surgery (Table 1, Fig. 1). The abdominoplasty group showed the largest mean weight gain (3.55 \pm $8.29 \mathrm{~kg}$ ) when compared with the bilateral breast reduction group $(2.60 \pm 4.09 \mathrm{~kg})$ and the control group $(2.66 \pm 2.84 \mathrm{~kg})$, but there was no significant difference between the groups. The patients in the abdominoplasty group had significantly greater body weight pre-surgery and showed the greatest changes in weight and BMI following surgery (Table 1). The abdominoplasty group showed a significantly greater fat mass $(5.52 \%, P \leq 0.032)$ compared with the control group following lipectomy.

\section{Prospective study}

The abdominoplasty group had a significant increase in body weight and BMI during the 18-month study period following surgery (Table 2, Fig. 2). Mean weight gain for the abdominoplasty group was $4.28 \pm 4.34 \mathrm{~kg}$. In the bilateral breast reduction group, pre-surgery to 18 months post-surgery there was a non-significant increase in weight (mean weight gain $0.67 \pm 5.03 \mathrm{~kg}$; Table 2, Fig. 2). In the abdominoplasty group, the change in body fat from pre-surgery to 18 months postsurgery was $7.94 \%$ and was not significant $(P \leq 0.075)$. In the bilateral breast reduction group, pre-surgery to 18 months post-surgery the mean difference in body fat was $0.04 \%$ and was not significant $(P \leq 0.909)$.

\section{Discussion}

The results of this study support observations in animal models that lipectomy is followed by an increase in body fat and confirm a questionnaire survey in humans that suggested weight gain following liposuction (12). The patients undergoing abdominoplasty were heavier before surgery and this may account for their greater increase in weight and BMI. It may be that the presurgery weight is an important factor in determining weight gain following surgery although this was not addressed in our study. It is possible that the energy regulatory mechanisms of the body act to prevent weight loss in individuals with abdominal obesity or visceral fatty content $(13,14)$. The larger but non-significant increase in body fat in abdominoplasty group compared with

Table 1 Group characteristics of the subjects in the retrospective study at pre-surgery and follow-up.

\begin{tabular}{llll}
\hline & Abdominoplasty & $\begin{array}{l}\text { Bilateral breast } \\
\text { reduction }\end{array}$ \\
\hline Sample size & 16 & 17 & $\begin{array}{l}\text { Carpal tunnel } \\
\text { syndrome release }\end{array}$ \\
Age (years) & $39.53 \pm 5.80$ & $40.05 \pm 12.46$ \\
Height $(\mathrm{m})$ & $1.63 \pm 0.06$ & $1.61 \pm 0.05$ \\
Mean fat removed $(\mathrm{kg})$ & $1.00 \pm 0.84$ & $1.27 \pm 0.55$ \\
Mean weight pre-surgery $(\mathrm{kg})$ & $70.17 \pm 14.51^{\mathrm{a}}$ & $67.84 \pm 9.57$ \\
Mean weight 18 months $(\mathrm{kg})$ & $73.91 \pm 14.82^{\mathrm{a}}$ & $70.40 \pm 9.45$ \\
Mean weight gain $(\mathrm{kg})$ & $3.55 \pm 8.29^{*}$ & $2.60 \pm 4.09^{*}$ \\
Mean BMl pre-surgery $\left(\mathrm{kg} / \mathrm{m}^{2}\right)$ & $26.44 \pm 5.48$ & $26.01 \pm 3.26$ \\
Mean BMl 18 months $\left(\mathrm{kg} / \mathrm{m}^{2}\right)$ & $27.74 \pm 5.14$ & $27.05 \pm 3.36$ \\
Body fat 18 months $(\%)$ & $37.21 \pm 5.63^{\mathrm{a}}$ & $35.10 \pm 5.19$ \\
Duration of follow-up $(\mathrm{months})$ & $15.07 \pm 4.23$ & $15.53 \pm 2.74$ \\
\hline
\end{tabular}

*Significant increase from the baseline $P \leq 0.05$. Values are means and S.D

${ }^{a}$ Abdominoplasty group significantly different to carpal tunnel syndrome release group. 
Table 2 Group characteristics of the subjects in the prospective study at pre-surgery and follow-up.

\begin{tabular}{|c|c|c|}
\hline & Abdominoplasty & $\begin{array}{l}\text { Bilateral breast } \\
\text { reduction }\end{array}$ \\
\hline Sample size & 7 & 12 \\
\hline Age (years) & $35.57 \pm 6.24$ & $38.5 \pm 8.89$ \\
\hline Height $(\mathrm{m})$ & $162.71 \pm 3.86$ & $162.25 \pm 5.61$ \\
\hline Mean fat removed $(\mathrm{kg})$ & $1.77 \pm 1.04$ & $3.22 \pm 0.34$ \\
\hline $\begin{array}{l}\text { Mean weight } \\
\text { pre-surgery }(\mathrm{kg})\end{array}$ & $70.91 \pm 8.89$ & $81.88 \pm 18.33$ \\
\hline $\begin{array}{l}\text { Mean weight } 18 \\
\text { months }(\mathrm{kg})\end{array}$ & $75.20 \pm 10.67^{*}$ & $82.55 \pm 18.59$ \\
\hline Mean weight gain $(\mathrm{kg})$ & $4.28 \pm 4.34$ & $0.67 \pm 5.03$ \\
\hline $\begin{array}{l}\text { Mean BMI } \\
\text { pre-surgery }\left(\mathrm{kg} / \mathrm{m}^{2}\right)\end{array}$ & $26.87 \pm 2.63$ & $31.12 \pm 6.77$ \\
\hline $\begin{array}{l}\text { Mean BMI } 18 \\
\text { months }\left(\mathrm{kg} / \mathrm{m}^{2}\right)\end{array}$ & $28.53 \pm 3.44^{*}$ & $31.33 \pm 6.78$ \\
\hline $\begin{array}{l}\text { Mean body fat } \\
\text { pre-surgery }(\mathrm{kg})\end{array}$ & $25.07 \pm 4.52$ & $33.9 \pm 5.67$ \\
\hline $\begin{array}{l}\text { Mean body fat at } 18 \\
\text { months }(\mathrm{kg})\end{array}$ & $29.39 \pm 6.32$ & $34.68 \pm 7.34$ \\
\hline $\begin{array}{l}\text { Duration of } \\
\text { follow-up (months) }\end{array}$ & 18 & 18 \\
\hline
\end{tabular}

*Significant increase from the baseline $P \leq 0.05$. Values are means and S.D.

bilateral breast reduction group suggests that there may be differences in the regulatory mechanisms that depend upon the depot of fat removed. Of relevance, femoral adipocytes from women have been shown to have a greater lipoprotein lipase activity than abdominal or mammary adipocytes and the difference in fat depot may be regulated by oestrogen levels (15). In addition, a variety of metabolic differences have been reported in rodents between mammary and abdominal fat (16).

The lack of statistical significant difference in body weight changes between the bilateral breast reduction group and the carpal tunnel syndrome group suggests that most individuals in the two groups had similar characteristics or that the two groups as a whole were very similar in terms of body weight gain and BMI changes. Pernia et al. (17) found a higher prevalence of carpal tunnel syndrome in women who had been admitted to

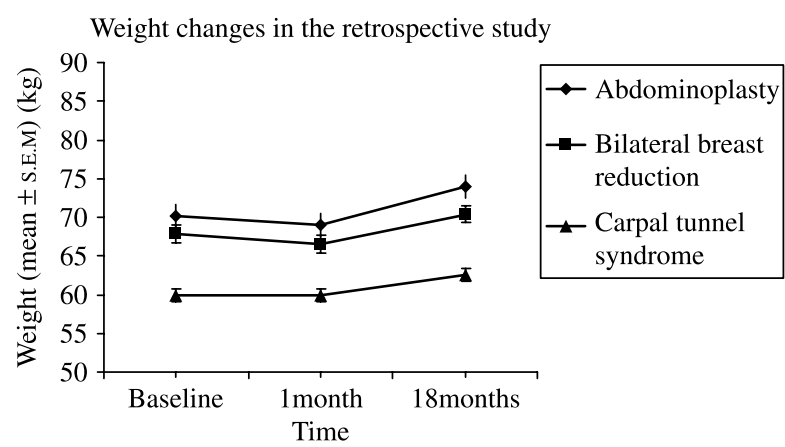

Figure 1 Mean weight change in abdominoplasty group, bilateral breast reduction group and carpal tunnel syndrome release group in the retrospective study at pre-surgery, at 1 month and 18 months following surgery respectively.

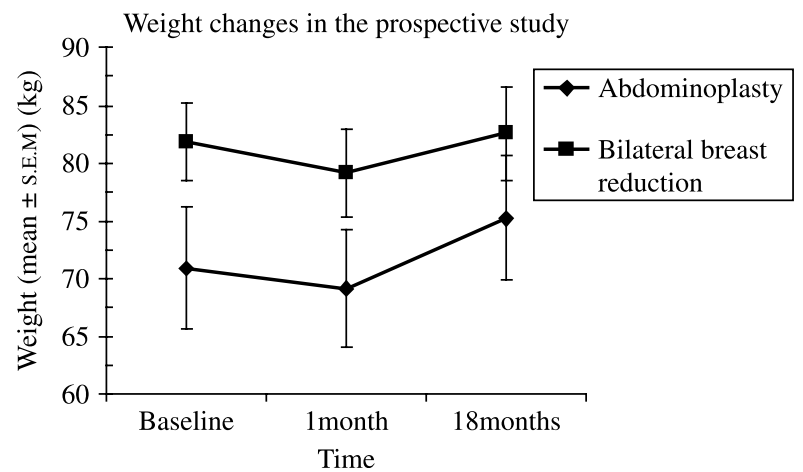

Figure 2 Mean weight change in abdominoplasty group and bilateral breast reduction group in the prospective study at presurgery, at 1 month and 18 months following surgery respectively.

hospital for breast reduction than in those with smaller breasts and they concluded that breast size was a significant predictor of carpal tunnel syndrome. They argued that women who had mammary hypertrophy had an increased risk of carpal tunnel syndrome. It is known that some diseases such as hypothyroidism, diabetes mellitus, wrist osteoarthritis and obesity are associated with carpal tunnel syndrome (18).

In our prospective study, weight increase was seen in both the abdominoplasty and bilateral breast reduction groups. However, higher weight gain was seen with the abdominoplasty group possibly reflecting previous weight history. Previous studies and ours did not address lifestyle changes. Changes in dietary intake and exercise could influence the metabolic response to surgery and this should be addressed in future studies.

Our results suggest that lipectomy was of limited value in body weight control since weight gain was observed following these procedures. This weight gain probably reflects the expected gain in weight without surgery as a similar finding is observed in patients who have undergone surgery without lipectomy. Therefore, these results highlight the limitation of this procedure as a weight control measure. Further prospective studies are required with control groups that match weight and BMI to confirm the above findings.

\section{Acknowledgements}

Our sincere thanks go to patients and other volunteers who agreed to help and for their cooperation with the protocols. Also, we would like to acknowledge the Faculty of Medicine Research Committee, University of Leeds for the financial support for most of the work. Our thanks extend to the Ministry of Health and the Postgraduate Institute of Medicine, Sri Lanka. A S Rinomhota and D U S Bulugahapitiya contributed equally to this work. 


\section{References}

1 Commons GW, Halperin B \& Chang CC. Large-volume liposuction: a review of 631 consecutive cases over 12 years. Plastic and Reconstructive Surgery 2001108 1753-1763.

2 Klein S, Fontana L, Young VL, Coggan AR, Kilo C, Patterson BW \& Mohammed BS. Absence of an effect of liposuction on insulin action and risk factors for coronary heart disease. New England Journal of Medicine $20043502549-2557$.

3 Davis DA, Pellowski DM \& Donahoo WT. Acute and 1-month effect of small-volume suction lipectomy on insulin sensitivity and cardiovascular risk. International Journal of Obesity 200630 1217-1222.

4 Giugliano G, Nicoletti G, Grella E, Giugliano F, Esposito K, Scuderi N \& D'andrea F. Effect of liposuction on insulin resistance and vascular inflammatory markers in obese women. British Journal of Plastic Surgery 200457 190-194.

5 Chlouverakis C \& Hojnicki D. Lipectomy on obese hyperglycaemic mice. Metabolism 197423 133-137.

6 Faust IM, Johnson PR \& Hirsch J. Adipose tissue regeneration following lipectomy. Science 1977197 391-396.

7 Dark J, Forger NG \& Zucker I. Rapid recovery of body mass after surgical removal of adipose tissue in ground squirrels. PNAS 1984 $812270-2272$.

8 Forger NG, Dark J \& Zucker I. Recovery of adipose tissue after lipectomy in female ground squirrels. Canadian Journal of Zoology $198664128-131$.

9 Hamilton JM \& Wade GN. Lipectomy does not impair fattening induced by short photoperiods or high fat diets in female Syrian hamsters. Physiology and Behavior 198843 85-92.

10 Hausman DB, Lu J, Ryan DH, Flatt WP \& Harris RB. Compensatory growth of adipose tissue after partial lipectomy: involvement of serum factors. Experimental Biology and Medicine 2004229 $512-520$.
11 Lacy EL \& Bartness TJ. Autologous fat transplants influence compensatory white adipose tissue mass increases after lipectomy. American Journal of Physiology. Regulatory, Integrative and Comparative Physiology 2004286 R61-R70.

12 Dillerud E \& Haheim LL. Long term results of blunt suction lipectomy assessed by a patient questionnaire survey. Plastic and Reconstructive Surgery 199392 35-42.

13 Roberts SR, Pi-Sunyer FX, Dreher M, Hahn R, Hill JO, Kleinman RE, Peters JC, Ravussin E, Rolls BJ, Yetley E \& Booth SL. Physiology of fat replacement and fat reduction: effects of dietary and fat substitutes on energy regulation. Nutrition Reviews 199856 S29-S41.

14 Saltzman E, Dallal GE \& Roberts SB. Effects of high fat and low fat diets on voluntary energy intake and substrate oxidation: studies in identical twins consuming diets matched for energy density, fiber and palatability. American Journal of Clinical Nutrition 1997 66 1332-1339.

15 Rebuffe-Scrive M, Eldh J, Hafstrom LO \& Bjorntorp P. Metabolism of mammary, abdominal, and femoral adipocytes in women before and after menopause. Metabolism 198635 792-797.

16 Neville MC, Medina D, Monks J \& Hovey RC. The mammary fat pad. Journal of Mammary Gland Biology and Neoplasia 19983 109-116.

17 Pernia LR, Ronel DN, Sleeper JD \& Miller H. Carpal tunnel syndrome in women undergoing reduction mammaplasty. Plastic and Reconstructive Surgery 2000105 1314-1319.

18 Atcheson SG, Wards JR \& Lowe W. Concurrent medical disease in work related carpal tunnel syndrome. Archives of Internal Medicine 1998158 1506-1512.

Received 7 December 2007

Accepted 15 December 2007 